\title{
BMJ Open Incidence and trend of preterm birth in China, 1990-2016: a systematic review and meta-analysis
}

\author{
Shiwen Jing, ${ }^{1,2}$ Chang Chen, ${ }^{1,2}$ Yuexin Gan, ${ }^{2}$ Joshua Vogel, ${ }^{3}$ Jun Zhang (D) ${ }^{1,2}$
}

To cite: Jing S, Chen C, Gan Y, et al. Incidence and trend of preterm birth in China, 19902016: a systematic review and meta-analysis. BMJ Open 2020;10:e039303. doi:10.1136/ bmjopen-2020-039303

\section{- Prepublication history and} additional material for this paper are available online. To view these files, please visit the journal online (http://dx.doi org/10.1136/bmjopen-2020039303).

\section{SJ, CC and YG contributed} equally.

SJ, CC and YG are joint first authors.

Received 10 April 2020 Revised 19 0ctober 2020 Accepted 24 November 2020

\section{Check for updates}

(C) Author(s) (or their employer(s)) 2020. Re-use permitted under CC BY-NC. No commercial re-use. See rights and permissions. Published by BMJ.

${ }^{1}$ School of Public Health, Shanghai Jiao Tong University School of Medicine, Shanghai, China

${ }^{2}$ Ministry of Education-Shanghai Key Laboratory of Children's Environmental Health, Xinhua Hospital, Shanghai Jiao Tong University School of Medicine, Shanghai, China

${ }^{3}$ Maternal, Child and Adolescent Health Program, Burnet Institute, Melbourne, Victoria, Australia

Correspondence to

Dr Jun Zhang;

junjimzhang@sina.com

\section{ABSTRACT}

Objectives To update the WHO estimate of preterm birth rate in China in 1990-2016 and to further explore variations by geographic regions and years of occurrence. Design Systematic review and meta-analysis.

Data sources Pubmed, Embase, Cochrane Library and Sinomed databases were searched from 1990 to 2018. Eligibility criteria Studies were included if they provided preterm birth data with at least 500 total births. Reviews, case-control studies, intervention studies and studies with insufficient information or published before 1990 were excluded. We estimated pooled incidence of preterm birth by a random effects model, and preterm birth rate in different year, region and by livebirths or all births in subgroup analyses.

Results Our search identified 3945 records. After the removal of duplicates and screening of titles and abstracts, we reviewed 254 studies in full text and excluded 182 , leaving 72 new studies. They were combined with the 82 studies included in the WHO report (154 studies, 187 data sets in total for the meta-analysis), including 24039084 births from 1990 to 2016. The pooled incidence of preterm birth in China was 6.09\% (95\% Cl 5.86\% to 6.31\%) but has been steadily increasing from $5.36 \%(95 \% \mathrm{Cl} 4.89 \%$ to $5.84 \%$ ) in $1990-1994$ to $7.04 \%$ (95\% Cl $6.09 \%$ to $7.99 \%$ ) in 2015-2016. The annual rate of increase was about $1.05 \%$ (95\% Cl $0.85 \%$ to $1.21 \%$ ). Northwest China appeared to have the highest preterm birth rate $(7.3 \%$, $95 \% \mathrm{Cl} 4.92 \%$ to $9.68 \%$ from 1990 to 2016).

Conclusions The incidence of preterm birth in China has been rising gradually in the past three decades. It was $7 \%$ in 2016. Preterm birth rate varied by region with the West having the highest occurrence.

\section{INTRODUCTION}

Preterm birth before 37 completed weeks of gestation $^{1}$ is often considered as one of the indicators reflecting a country's health level and social development. Complications of preterm birth is the leading cause of child under-5 mortality globally and ranked first in the causes of perinatal mortality in China. ${ }^{23}$ The survival of preterm infants is at a greater risk of health problems both in the short and longer terms. ${ }^{4}$ In addition to the direct health problems and parenting psychological stress, ${ }^{5}$ preterm birth also causes enormous healthcare costs. ${ }^{67}$ Data from Germany showed that

\section{Strengths and limitations of this study}

This systematic review focused on the current status of preterm birth in China and summarised preterm birth rate over the past three decades.

- The meta-analysis updated the estimate of preterm birth rate over time and compared among geographic regions in China.

- The inclusion of stillbirth increased preterm birth rate, which calls for a standardised definition for international comparisons.

- Most included studies lacked information on the subtypes of preterm birth and the method of gestational age estimation, causing in-depth analysis difficult.

the average health costs of a preterm infant in the first year were $€ 9717$ EUR higher than that of a full-term infant. ${ }^{8}$ In 2005, it was estimated by the Institute of Medicine that the socioeconomic burden associated with preterm birth was at least US\$26 billion per year in the USA. ${ }^{9}$

The WHO estimates that the global preterm birth rate was $9.8 \%$ (uncertainty interval (UI): $8.3 \%-10.9 \%$ ) in $2000,11.1 \%$ (UI: $9.1 \%-13.4 \%$ ) in 2010 and $10.6 \%$ (UI: $9.0 \%-12.0 \%$ ) in $2014 .^{1011}$ Increasing preterm birth rates are affected by multiple factors, including an increasing proportion of pregnant women over 34 years old, greater use of assisted reproduction technology and increasing number of multiple births. ${ }^{12}$ Improvement in maternal and perinatal healthcare increases survival of extremely preterm and very preterm infants, who otherwise might have been stillbirths. ${ }^{13}$ A 2005 study from 16 provinces in China showed that the incidence of preterm birth among 42139 livebirths was $7.8 \% .^{15}$ In 2011 , Zou et al conducted a multicentre survey including 107905 livebirths from 14 provinces in China reporting a preterm birth rate of $7.1 \%,{ }^{16}$ which differed substantially from the incidence of $11.0 \%$ of singleton livebirths from 
63 tertiary hospitals in 23 provinces in China between 2011 and 2014. ${ }^{17}$ Yet our multicentre cross-sectional survey involving 89 hospitals in 25 provinces in China has showed that the incidence of preterm birth was $7.3 \%$ between 2015 and $2016 .{ }^{18}$ In addition to the variations among different studies, the trend of preterm birth rate in China over the past three decades remains unclear. It is also worth noting that China opened two-child policy in 2015. ${ }^{19}$ As more families choose to have a second baby, whether the incidence of preterm birth is impacted needs to be explored. Therefore, our study aims to update the WHO estimate of preterm birth rate in China from 2014 to 2016 and to further explore variations by geographic regions and years of occurrence.

\section{METHODS}

This study was reported according to the Preferred Reporting Items for Systematic Reviews and Meta-analyses guidelines (online supplemental table S1).

\section{Search strategy}

Recently, WHO published a review on global, regional and national estimates of levels of preterm birth rate in $2014 .{ }^{11}$ Of note, the literature search was performed in February 2016 and articles published from 1990 to 2016 were screened. Our team participated in the study and conducted literature review of Chinese literature. This study is an update of the estimate for China. We followed the same search strategy and data extraction method as the previous paper for the maximal compatibility. In February 2019, we searched articles published from 2016 to 2018 in the same databases, including Pubmed, Embase, Cochrane Library and Sinomed using the same term as 'preterm birth', 'preterm labour', 'preterm delivery', 'premature labour', 'premature birth', 'premature delivery', 'pprom' or 'premature foetus membrane rupture', cross-referenced with 'China', without language restrictions but restricted to the six most highly cited Chinese medical journals in the Sinomed database. The search strategy is found in online supplemental table S2. Since the publication year of articles in our search had overlapped with WHO's search, we removed the duplicate articles in the title and abstract screening step. It should also be noted that there was, on average, a 2-year time lag between the study year and publication year. Thus, while our literature search was up to 2018, the study year was up to 2016.

\section{Selection criteria}

Studies were eligible if preterm birth rate was reported in at least 500 total births in Chinese population. ${ }^{20}$ Reports using livebirths or all births as the denominator were all eligible. We excluded reviews, case-control studies, experimental studies or those lacking sufficient information to determine the preterm birth rate. Studies collected before 1990 (or where the time period of collection was not reported) were not eligible. Where there were multiple reports from the same study population, we used only the data with most comprehensive information. Studies focusing on high-risk population only or reporting preterm birth rate less than $3 \%$ were also excluded on the basis of biological implausibility. ${ }^{21}$

\section{Data extraction and quality assessments}

After removing duplicates, two reviewers screened all titles and abstracts and then assessed the full text of potentially eligible articles independently. For each eligible report, extracted data including author, publication year, region, study design, year of data collection, method of estimating gestational age (GA), definition of preterm birth (per 100 livebirths or all births, singletons or singletons and multiples) and rate of preterm birth. A midpoint year was assigned to each study. Any disagreements were resolved by discussion or a third reviewer.

We assessed the quality of the included studies by the scales recommended by the Agency for Healthcare Research and Quality (AHRQ). For cross-sectional studies, we used a scoring approach of 11 items to grade quality, and publications scored 8-11 points were deemed to be of high quality, whereas a score of 4-7 represented moderate quality and a score of 0-3 represented low quality. ${ }^{22}$ For cohort studies, we used the NewcastleOttawa Scale recommended by AHRQ to grade quality, which contains three perspectives including the selection of the study groups, the comparability of the groups and the ascertainment of either the exposure or the outcome of interest. ${ }^{23}$ Publications with a total score of $7-11$ were deemed to be of high quality.

\section{Statistical analyses}

To calculate the preterm birth rate in China, we conducted a meta-analysis of the included studies using R V.3.4.4. We evaluated the heterogeneity among studies using both the Cochran $Q$ test statistic and $\mathrm{I}^{2}$ statistic and assumed a random effects model because of a clear heterogeneity in the included studies. Subgroup analyses and meta-regression were conducted to explain the potential sources of heterogeneity. Factors that were investigated included the midpoint year of data collection, administrative region, method of estimating GA and the definition of preterm birth. In our analysis, we calculated the preterm birth rate in livebirths from the reports using livebirths as the denominator and all births from the reports using all births as the denominator, respectively. All studies (regardless of denominator population) were used to calculate the preterm birth rate. Publication bias was assessed by funnel plot and Egger's linear regression tests. The annual rate of increase $=\left(\mathrm{PTB}_{2015-2016} / \mathrm{PTB}_{1990-}\right.$ $\left.{ }_{1994}\right)^{(1 / 26)}-1\left(\mathrm{PTB}_{2015-2016}\right.$ : the preterm birth rate in $2015-$ 2016, $\mathrm{PTB}_{1990-1994}$ : the preterm birth rate in 1990-1994).

\section{Patient and public involvement}

There was no involvement of patients or the public in any part of this research. 


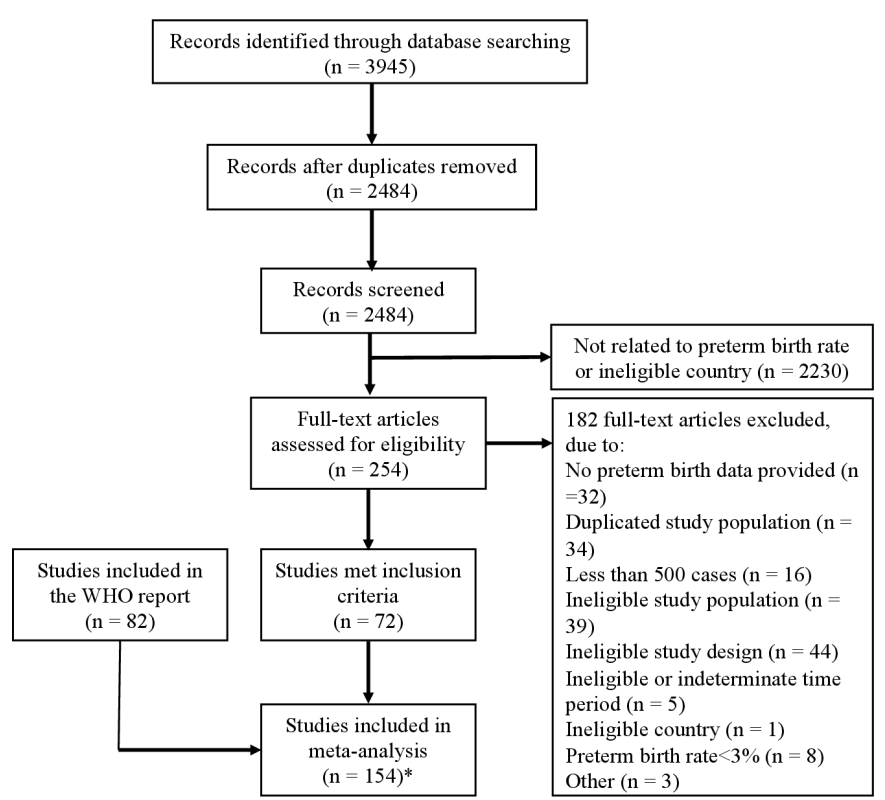

Figure 1 Study selection. *The 154 eligible studies included 187 datasets.

\section{RESULTS}

A total of 3945 records were identified. After removal of duplicates and initial screening on the basis of the title and abstract, we reviewed 254 studies in full text. Of these publications, 182 articles were excluded, including 44 were ineligible study design, 39 investigated patients with high-risk for preterm birth, 34 had a duplicated population with other studies, 32 did not provide preterm birth data, 16 had a sample size fewer than 500 patients, 8 had a preterm birth rate less than $3 \%, 5$ had ineligible or unknown year of data collection and 4 were from out of China or had other reasons. After exclusions, we kept 154 studies in the meta-analysis, 82 of which were included in the WHO report ${ }^{11}$ while 72 studies were new. These studies employed 187 data sets (figure 1 and online supplemental table S3). ${ }^{161724-175}$

These studies were conducted in seven administrative regions of China, including 41 from the East, 40 from the North, 18 from the South, 16 from the Central, 9 from the Southwest, 6 from the Northwest, 1 from the Northeast, 17 from Hong Kong, Macau and Taiwan and the rest of 39 from multiple provinces. Of the 187 data sets, 110 calculated preterm birth rate in livebirths only, 15 in all births (livebirths and stillbirths) and other 62 data sets did not specify live birth or all births. In terms of epidemiological design, 61 were cross-sectional studies and 93 were cohort studies. According to the quality criteria recommended by AHRQ, 42 studies were high quality, 100 were moderate quality and the remaining 12 were low quality. All included studies defined preterm birth as a delivery before 37 weeks of gestation. Thirty-nine studies estimated GA by last menstrual period (LMP) combined with ultrasound, 39 studies estimated GA by LMP, 5 studies estimated by ultrasound. Among 154 studies, 97 studies included singletons only, 25 studies included both singletons and multiples and 32 studies are unknown.

The estimated pooled preterm birth rate in China from 1990 to 2016 was $6.09 \%$ (95\% CI $5.86 \%$ to $6.31 \%$ ) overall, ranging from $3 \%$ to $16.28 \%$, with considerable heterogeneity $\left(\mathrm{I}^{2}=99.8 \%, \mathrm{p}<0.0001\right)$. The estimated preterm birth rate by region was as follows: $5.67 \%(95 \% \mathrm{CI} 4.26 \%$ to $7.09 \%$ ) in the Central, $6.19 \%$ (95\% CI $5.66 \%$ to $6.73 \%$ ) in the East, $5.48 \%$ (95\% CI $4.96 \%$ to $6.01 \%$ ) in the North, $3.8 \%(95 \%$ CI $2.4 \%$ to $5.21 \%)$ in the Northeast, $7.3 \%$ (95\% CI $4.92 \%$ to $9.68 \%$ ) in the Northwest, $6.14 \%$ (95\% CI $5.96 \%$ to $6.32 \%$ ) in the South, $6.96 \%$ (95\% CI $4.94 \%$ to $8.99 \%$ ) in the Southwest and $6.13 \%$ (95\% CI $5.55 \%$ to $6.71 \%$ ) in Hong Kong, Macau and Taiwan. Only one study was from the Northeast, thus the preterm birth rate may not be reliable. (figure 2)

The pooled preterm birth rate in China was $6.00 \%$ (95\% CI $5.69 \%$ to $6.3 \%)$ for livebirths and $7.01 \%(95 \%$ CI $5.9 \%$ to $8.12 \%$ ) for all births (livebirths and stillbirths). The rate has been increasing in the past three decades, from $5.36 \%$ (95\% CI $4.89 \%$ to $5.84 \%$ ) in $1990-1994$ to $7.04 \%$ (95\% CI $6.09 \%$ to $7.99 \%$ ) in 2015-2016 (table 1). The average annual rate of increase was $1.05 \%$ (95\% CI $0.85 \%$ to $1.21 \%)$.

Univariate meta-regression analysis suggested that the midpoint year $(\mathrm{p}<0.001)$, administration region $(\mathrm{p}=0.009)$, definition of preterm birth (livebirths/all births $(p=0.021)$, singletons or singletons and multiples $(\mathrm{p}=0.013))$ and method of estimating GA $(\mathrm{p}=0.095)$ might have contributed to the heterogeneity, whereas we detected no significant differences in quality level of study $(\mathrm{p}=0.376)$. We further conducted multivariate metaregression, which showed that midpoint year, administration region, and definition of preterm birth (singletons or singletons and multiples) might be sources of heterogeneity. The funnel plot did not suggest any publication bias ( $\mathrm{p}=0.097$ ) (figure 3).

We performed a sensitivity analysis where the low-quality studies were excluded. The results remained essentially the same (online supplemental table S4), confirming that the results were unlikely confounded by the quality of studies.

\section{DISCUSSION}

Our study shows that the pooled preterm birth rate in China was $6.09 \%$ (95\% CI $5.86 \%$ to $6.31 \%$ ) between 1990 and 2016. The incidence of preterm birth has been increasing in China in the past three decades, from $5.36 \%$ (95\% CI $4.89 \%$ to $5.84 \%)$ in $1990-1994$ to $7.04 \%$ (95\% CI $6.09 \%$ to $7.99 \%$ ) in 2016 . The annual rate of increase was $1.05 \%$ (95\% CI $0.85 \%$ to $1.21 \%$ ). Preterm birth rate differed by regions, among which West China showed the highest preterm birth rate.

Preterm birth is officially defined as a delivery between 28 and 37 completed weeks of gestation in China. ${ }^{176}$ With the development and popularisation of prenatal diagnosis and perinatal care, more and more compromised 

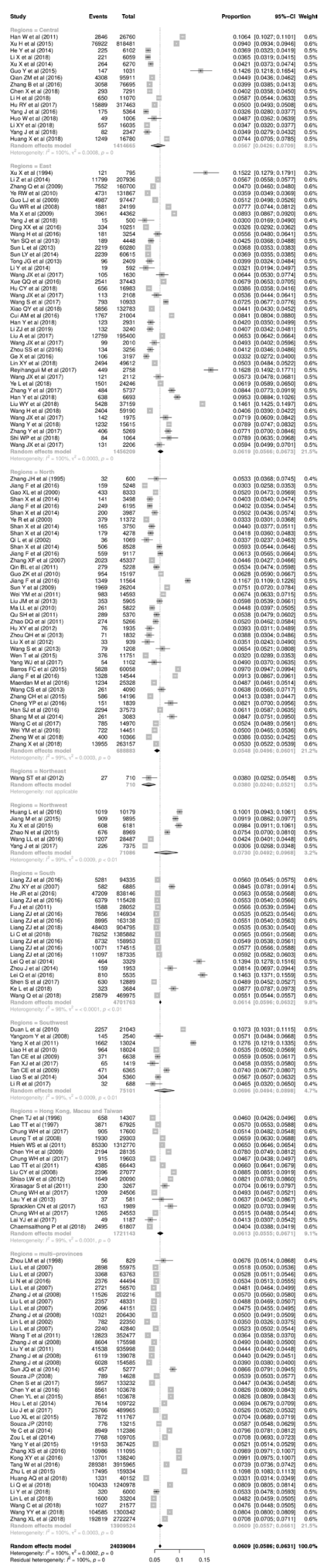

Figure 2 Random effects meta-analysis of preterm birth in China. fetuses are recognised and born even before 28 weeks of gestation. Many of these extremely preterm births can now survive and included in the statistics of preterm birth. Iatrogenic preterm birth related to medical intervention accounted for a large proportion of preterm birth in China, ${ }^{18}$ which may be one of the reasons for the gradual increase in preterm birth rate in recent years. In addition, inclusion of stillbirths in the denominator population increased the overall preterm birth rate. Similarly, Morisaki et al found that in a multicountry analysis of the WHO Multi-Country Survey on Maternal and Newborn Health that compared with the preterm birth rate based on livebirths alone, the inclusion of stillbirths had substantially increased the preterm birth rate, which could reflect international disparities in perinatal health more accurately. ${ }^{177}$ Their findings are in line with our finding in our univariate meta-regression that preterm birth rate was higher in all births $(7.01 \%, 95 \%$ CI $5.9 \%$ to $8.12 \%)$ than that in livebirths only $(6.0 \%, 95 \%$ CI $5.69 \%$ to $6.3 \%$ ), indicating that preterm birth as a public health problem may be more severe than expected. Not only appropriate prevention and management strategies but also more research on aetiology and pathogenesis are needed to reduce preterm birth rate in China.

Assisted reproductive technology (ART) is being increasingly used in China. One nationwide survey of ART from 178 reproductive centres and 13 sperm banks demonstrated that total ART cycle procedures of in vitro fertilisation increased from 78002 during 1981-2004 to 393538 during 2005-2011 in China. ${ }^{178}$ ART is a known risk factor for preterm birth for both singleton and multiple pregnancies. ${ }^{179}$ Meanwhile, the risk of prematurity is much higher in twins than in singletons. ${ }^{180}$ Therefore, the popularity of ART may also be one of the possible reasons for the gradual increase in preterm birth rate in China since 1990. Recently installed two-child policy may also be a factor for the increasing preterm birth rate since 2015 as women who had second child were often in advanced age, which is a risk factor for preterm birth. ${ }^{179}$

Subgroup analysis in different administration regions showed that the preterm birth rate was highest in the West, of which the preterm birth rate was $7.3 \%$ (95\% CI 4.92\% to $9.68 \%$ ) in the Northwest and $6.96 \%$ (95\% CI $4.94 \%$ to $8.99 \%$ ) in the Southwest. The preterm birth rate in Hong Kong, Macau and Taiwan was estimated to be $6.13 \%$ (95\% CI $5.55 \%$ to $6.71 \%$ ), which was close to that in the Central and North China. The high preterm rate in the West may be associated with a lower socioeconomic status. ${ }^{181}$ On the other hand, the Northeast appeared to have the lowest preterm birth rate. Although only one study was included in our meta-analysis, the preterm birth rate in Northeast $(3.8 \%, 95 \%$ CI $2.4 \%$ to $5.21 \%)$ was in line with our multicentre survey in which the preterm birth rate was 5.2\% (95\% CI $4.4 \%$ to $6.0 \%) .{ }^{18}$ Studies showed that height is inversely associated with the risk of preterm birth. ${ }^{182}$ Since women in Northeast China is generally taller, ${ }^{183}$ this may partially explain the lowest preterm birth rate in that region. It is also a possibility that as the fetuses there tend 


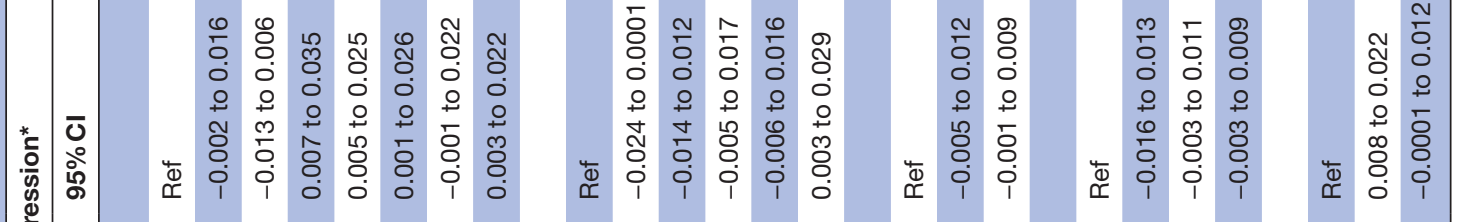

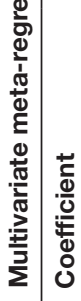

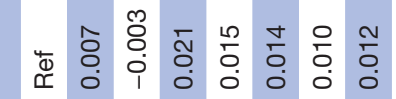

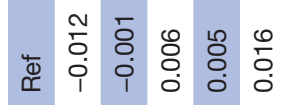

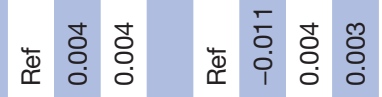

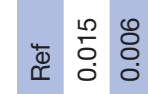

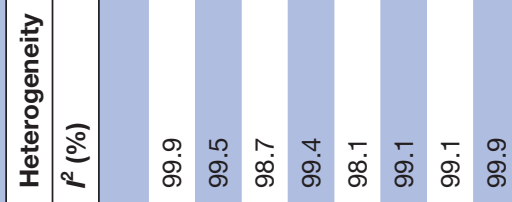

ஸि

ஜே.

ஓே

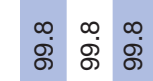

ת.

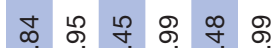

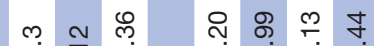

우 눙 훙

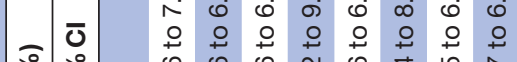

นأ

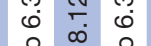

00

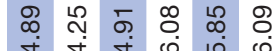

$\begin{array}{lll}0 & 0 \\ 0 & 0 & 0 \\ 0 & 0 & 0 \\ 0 & 0 & 0 \\ 10 & 0\end{array}$

ब

○)

焉

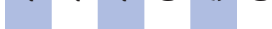

言

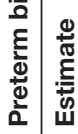

仓ิ宀

లூ

우 ธิ ชิ

ำ ㅇํㅇ 웅

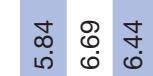

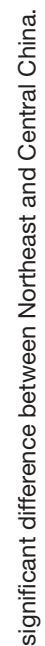

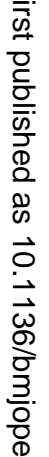

กิ

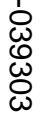

온

$\vec{N}$

$\nabla_{\mathbb{D}}$

$\frac{\Phi}{3}$

N

일

흠

ㅇํㅇ

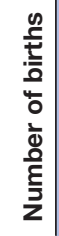

\&

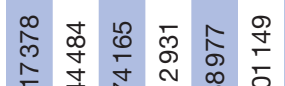

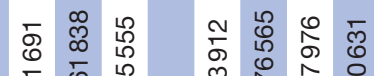

ㅇำ

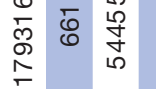

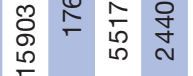

$\begin{array}{lll}0 & 0 \\ 0 & 0 & 0 \\ 0 & 0 & 0 \\ 0 & 0 & 0 \\ 1 & - & 0\end{array}$

ㅇํ

œำ

ले

요

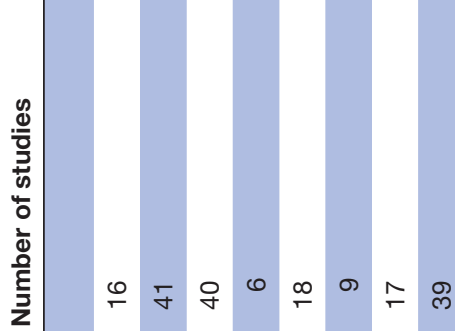

๘

욷 는 ช

เ্

స్ ঙ্ল

त्.

塞 


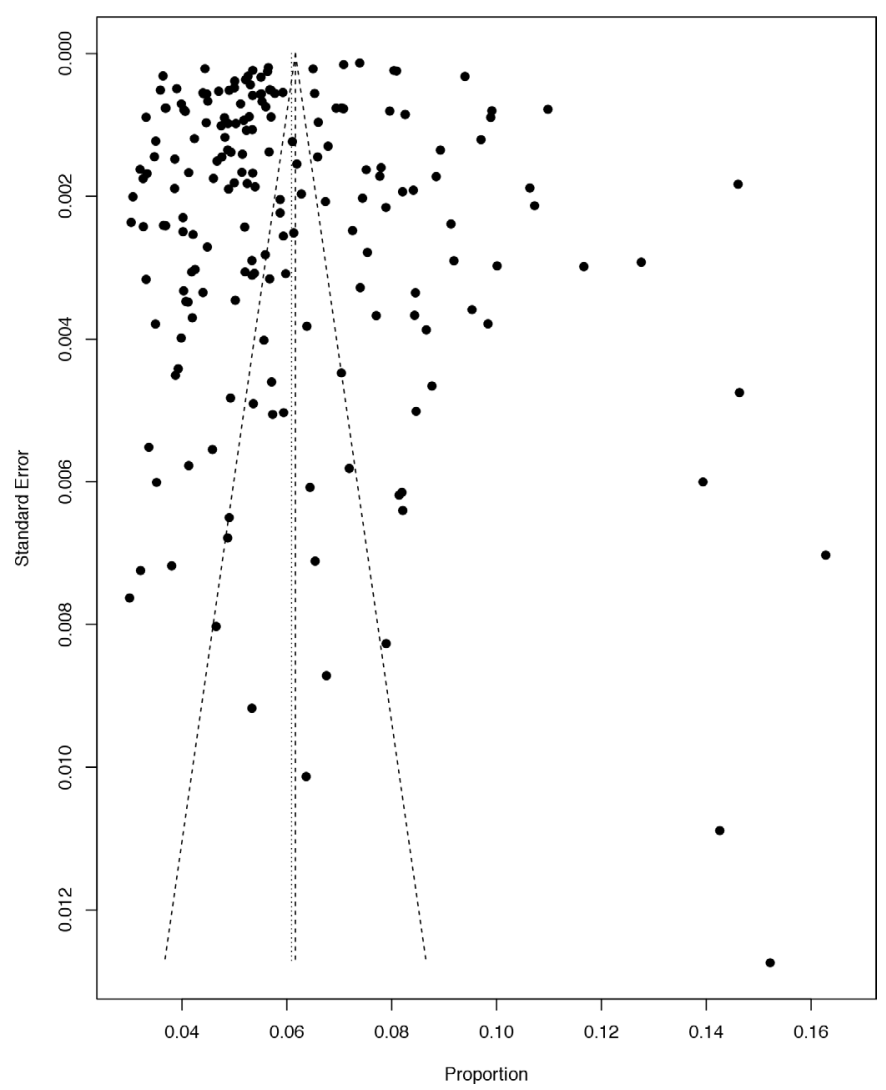

Figure 3 Funnel plot of preterm birth prevalence as a function of prevalence estimate SE.

to be larger, ultrasound might overestimate the GA, and therefore reduce the incidence of preterm birth.

Our meta-analysis has some limitations. First, although the upper limit of the definition of preterm birth is globally accepted as 36 weeks +6 days, the lower limit ranges from 20 to 28 weeks in different part of the world. ${ }^{11}$ Many reports in our study did not provide a clear lower limit of gestational week. Second, ultrasound early in pregnancy is considered the gold standard for assessment of GA, but many studies did not specify the method of assessing GA. Though LMP combined with ultrasound to assess GA was predominant assessment method in China, no specific data are available. However, it is likely that the degree of ultrasound use in pregnancy varies with availability of medical resources in different settings and regions. Women only relied on the first day of the LMP might bias the preterm birth rate. The high preterm birth rate in low socioeconomic regions may result from both misclassification and truly higher preterm birth rate. Third, most studies did not provide more detailed information on the subtypes of preterm birth (spontaneous onset, iatrogenic and rupture of the membranes) or the causes of preterm birth, making more in-depth analysis difficult.

Subgroup analysis did not explain the specific causes of heterogeneity $\left(\mathrm{I}^{2}>50 \%\right)$. We conducted univariate meta-regression analysis on various sources and identified significant differences in year, regions and definition of preterm birth, suggesting that these factors might be the main cause of heterogeneity in this meta-analysis.
Meanwhile, multivariate meta-regression showed that the West had a higher preterm birth rate than other regions. Compared with 1990-1994, preterm birth rate was higher in 2015-2016. Additionally, the rate was higher in all births than in singletons only. Method of estimating GA was not associated with heterogeneity.

In summary, our meta-analysis showed that the preterm birth rate has been rising in China over the past three decades. It was around 7\% in 2016. Preterm birth rate varied by region with the West having the highest occurrence.

Contributors JZ and JV conceived and designed the study. Screening was carried out by SJ, CC and YG. SJ and CC analysed the data and drafted the manuscript. All author commented and revised the final version of this article.

Funding This work was supported by the Shanghai Municipal Health Commission (GWIV.26) and the Shanghai Jiao Tong University School of Medicine Doctoral Student Innovation Fund, grant number BXJ201907.

Competing interests None declared.

Patient consent for publication Not required.

Provenance and peer review Not commissioned; externally peer reviewed.

Data availability statement All data relevant to the study are included in the article or uploaded as supplementary information.

Supplemental material This content has been supplied by the author(s). It has not been vetted by BMJ Publishing Group Limited (BMJ) and may not have been peer-reviewed. Any opinions or recommendations discussed are solely those of the author(s) and are not endorsed by BMJ. BMJ disclaims all liability and responsibility arising from any reliance placed on the content. Where the content includes any translated material, BMJ does not warrant the accuracy and reliability of the translations (including but not limited to local regulations, clinical guidelines, terminology, drug names and drug dosages), and is not responsible for any error and/or omissions arising from translation and adaptation or otherwise.

Open access This is an open access article distributed in accordance with the Creative Commons Attribution Non Commercial (CC BY-NC 4.0) license, which permits others to distribute, remix, adapt, build upon this work non-commercially, and license their derivative works on different terms, provided the original work is properly cited, appropriate credit is given, any changes made indicated, and the use is non-commercial. See: http://creativecommons.org/licenses/by-nc/4.0/.

ORCID iD

Jun Zhang http://orcid.org/0000-0003-1706-1611

\section{REFERENCES}

1 Who: recommended definitions, terminology and format for statistical tables related to the perinatal period and use of a new certificate for cause of perinatal deaths. modifications recommended by FIGO as amended October 14, 1976. Acta Obstet Gynecol Scand 1977;56:247-53.

$2 \mathrm{He}$ C, Liu L, Chu Y, et al. National and subnational all-cause and cause-specific child mortality in China, 1996-2015: a systematic analysis with implications for the sustainable development goals. Lancet Glob Health 2017;5:e186-97.

3 Liu L, Oza S, Hogan D, et al. Global, regional, and national causes of under-5 mortality in 2000-15: an updated systematic analysis with implications for the sustainable development goals. Lancet 2016;388:3027-35.

4 Platt MJ. Outcomes in preterm infants. Public Health 2014;128:399-403.

5 Singer LT, Salvator A, Guo S, et al. Maternal psychological distress and parenting stress after the birth of a very low-birth-weight infant JAMA 1999;281:799-805.

6 Howson CP, Kinney MV, McDougall L, et al. Born too soon: preterm birth matters. Reprod Health 2013;10:S1.

7 Khan KA, Petrou S, Dritsaki M, et al. Economic costs associated with moderate and late preterm birth: a prospective populationbased study. BJOG: Int J Obstet Gy 2015;122:1495-505. 
8 Jacob J, Lehne M, Mischker A, et al. Cost effects of preterm birth: a comparison of health care costs associated with early preterm, late preterm, and full-term birth in the first 3 years after birth. Eur $J$ Health Econ 2017:18:1041-6.

9 Institute of Medicine Committee on Understanding Premature B, Assuring Healthy $\mathrm{O}$. The National Academies Collection: Reports funded by National Institutes of Health. In: Behrman RE, Butler AS, eds. Preterm birth: causes, consequences, and prevention. Washington (DC: National Academies Press (US) National Academy of Sciences, 2007.

10 Blencowe H, Cousens S, Oestergaard MZ, et al. National, regional, and worldwide estimates of preterm birth rates in the year 2010 with time trends since 1990 for selected countries: a systematic analysis and implications. The Lancet 2012;379:2162-72.

11 Chawanpaiboon S, Vogel JP, Moller A-B, et al. Global, regional, and national estimates of levels of preterm birth in 2014: a systematic review and modelling analysis. Lancet Global Health 2019;7:e37-46.

12 Beck S, Wojdyla D, Say L, et al. The worldwide incidence of preterm birth: a systematic review of maternal mortality and morbidity. Bull World Health Organ 2010;88:31-8.

13 Kong X, Xu F, Wu R, et al. Neonatal mortality and morbidity among infants between 24 to 31 complete weeks: a multicenter survey in China from 2013 to 2014. BMC Pediatr 2016;16:174

14 Zeitlin J, Szamotulska K, Drewniak N, et al. Preterm birth time trends in Europe: a study of 19 countries. BJOG: Int J Obstet Gy 2013;120:1356-65.

15 Subspecialty T, Society P, Association CMJCJoCP. An initial epidemiologic investigation of preterm infants in cities of China, 2005.

16 Zou L, Wang X, Ruan Y, et al. Preterm birth and neonatal mortality in China in 2011. Int J Gynaecol Obstet 2014;127:243-7.

17 Zhu L, Zhang R, Zhang S, et al. [Chinese neonatal birth weight curve for different gestational age]. Zhonghua Er Ke Za Zhi 2015;53:97-103.

18 Chen C, Zhang JW, Xia HW, et al. Preterm birth in China between 2015 and 2016. Am J Public Health 2019;109:1597-604.

19 Feng W, Gu B, Cai Y. The End of China's One-Child Policy. Stud Fam Plann 2016;47:83-6.

20 Vogel JP, Chawanpaiboon S, Watananirun K, et al. Global, regional and national levels and trends of preterm birth rates for 1990 to 2014: protocol for development of World Health organization estimates. Reprod Health 2016;13:1-9.

21 Papageorghiou AT, Ohuma EO, Altman DG, et al. International standards for fetal growth based on serial ultrasound measurements: the fetal growth longitudinal study of the INTERGROWTH-21st project. The Lancet 2014;384:869-79.

22 R A, D C, C A, et al. Celiac disease. Rockville (MD: Agency for Healhcare Research and Quality (US), 2004.

23 GA W BS, OC D, et al. The Newcastle-ottawa scale (NOS) for assessing the quality for nonrandomised studies in meta-analysis. The Ottawa Hospital Research Institute, 2014.

24 Han W, Song J, Liu A, et al. Trends in live births in the past 20 years in Zhengzhou, China. Acta Obstet Gynecol Scand 2011;90:332-7.

$25 \mathrm{He} \mathrm{Y}$, Wen S, Tan H, et al. [Study on the influence of pregnancyinduced hypertension on neonatal birth weight and its interaction with other factors]. Zhonghua Liu Xing Bing Xue Za Zhi 2014;35:397-400.

26 Xu X, Tan H, Zhou S, et al. [Study on the application of BackPropagation Artificial Neural Network used the model in predicting preterm birth]. Zhonghua Liu Xing Bing Xue Za Zhi 2014;35:1028-31.

$27 \mathrm{Xu} \mathrm{H}$, Dai Q, Xu Y, et al. Time trends and risk factor associated with premature birth and infants deaths due to prematurity in Hubei Province, China from 2001 to 2012. BMC Pregnancy Childbirth 2015; 15:329.

28 Guo Y, Long X, Yao S. [Correlation between the myometrial thickness in the second trimester and preterm delivery in a prospective study]. Zhonghua Fu Chan Ke Za Zhi 2015;50:108-11.

29 Qian Z, Liang S, Yang S, et al. Ambient air pollution and preterm birth: a prospective birth cohort study in Wuhan, China. Int $J$ Hyg Environ Health 2016;219:195-203.

30 Yang J, Huo W, Zhang B, et al. Maternal urinary cadmium concentrations in relation to preterm birth in the healthy baby cohort study in China. Environ Int 2016;94:300-6.

31 Zhang B, Yang S, Yang R, et al. Maternal prepregnancy body mass index and small for gestational age births in Chinese women. Paediatr Perinat Epidemiol 2016;30:550-4.

32 Hu R, Chen Y, Zhang Y, et al. Association between vomiting in the first trimester and preterm birth: a retrospective birth cohort study in Wuhan, China. BMJ Open 2017;7:e017309.
33 Chen X, Li Y, Zhang B, et al. Maternal exposure to nickel in relation to preterm delivery. Chemosphere 2018;193:1157-63.

34 Huang X, Tan H, Cai M, et al. Gestational weight gain in Chinese women -- results from a retrospective cohort in Changsha, China. BMC Pregnancy Childbirth 2018;18:185.

35 Huo W, Xia W, Wu C, et al. Urinary level of triclosan in a population of Chinese pregnant women and its association with birth outcomes. Environ Pollut 2018;233:872-9.

$36 \mathrm{Li} \mathrm{H}$, Song LL, Shen LJ, et al. [Association between maternal body height and risk of preterm birth]. Zhonghua Liu Xing Bing Xue Za Zhi 2018;39:313-6.

37 Li X, Tan H, Luo M, et al. Exposure to firework chemicals from production factories in pregnant women and risk of preterm birth occurrence in Liuyang, China. $J$ Toxicol Environ Health $A$ 2018;81:154-9.

$38 \mathrm{Li} \mathrm{X}$, Liu Y, Liu F, et al. Analysis of short-term and sub-chronic effects of ambient air pollution on preterm birth in central China. Environ Sci Pollut Res Int 2018;25:19028-39.

39 Yang J, Liu Y, Liu H, et al. Associations of maternal iodine status and thyroid function with adverse pregnancy outcomes in Henan Province of China. J Trace Elem Med Biol 2018;47:104-10.

40 Xu X, Ding M, Li B, et al. Association of rotating shiftwork with preterm births and low birth weight among never smoking women textile workers in China. Occup Environ Med 1994;51:470-4.

$41 \mathrm{Li} \mathrm{Z,} \mathrm{Ye} \mathrm{R,} \mathrm{Zhang} \mathrm{L,} \mathrm{et} \mathrm{al.} \mathrm{Periconceptional} \mathrm{folic} \mathrm{acid}$ supplementation and the risk of preterm births in China: a large prospective cohort study. Int J Epidemiol 2014;43:1132-9.

42 Zhang Q, Ananth CV, Li Z, et al. Maternal anaemia and preterm birth: a prospective cohort study. Int J Epidemiol 2009;38:1380-9.

43 Ye R-W, Li H-T, Ma R, et al. [Prospective cohort study of pregnancyinduced hypertension and risk of preterm delivery and low birth weight]. Zhonghua Yu Fang Yi Xue Za Zhi 2010;44:70-4.

44 Guo L-jun, Ye R-wei, Wang G-xia, et al. [Birth weight distribution among premature infants and related social factors]. Zhonghua Liu Xing Bing Xue Za Zhi 2009;30:1243-7.

45 WR G, XT L, LP Y. Preterm infantile morbidity and mortality according to different gestational age and birth weight]. Chinese Journal Of Perinatal Medicine 2008;11:10-15.

46 Ma X, Huang C, Lou S, et al. The clinical outcomes of late preterm infants: a multi-center survey of Zhejiang, China. J Perinat Med 2009;37:695-9.

47 Li Y, Chen X, Chen S, et al. [A cohort study on the impacts of prepregnancy maternal body mass index, gestational weight gain on neonate birth status and perinatal outcomes in Fujian province]. Zhonghua Liu Xing Bing Xue Za Zhi 2014;35:635-40.

48 Yan S-qin, Xu Y-qing, Su P-yu, et al. [Relationship between folic acid supplements during peri-conceptional period and the adverse pregnancy outcomes: a cohort study]. Zhonghua Liu Xing Bing Xue Za Zhi 2013;34:1-4.

49 Tong J, Gu N, Li J, et al. Impact of gestational weight gain and prepregnant body mass index on pregnant outcomes. Chin $J$ Perinat Med 2013;16:561-5.

50 Sun L, Yue H, Sun B, et al. Estimation of birth population-based perinatal-neonatal mortality and preterm rate in China from a regional survey in 2010. J Matern Fetal Neonatal Med 2013;26:1641-8.

51 Sun L, Yue H, Sun B, et al. Estimation of high risk pregnancy contributing to perinatal morbidity and mortality from a birth population-based regional survey in 2010 in China. BMC Pregnancy Childbirth 2014:14:338.

$52 \mathrm{GeX}, \mathrm{Xu} Y \mathrm{YQ}$, Huang SH, et al. [Intrahepatic cholestasis of pregnancy and fetal outcomes: a prospective birth cohort study]. Zhonghua Liu Xing Bing Xue Za Zhi 2016;37:187-91.

53 Cui A-M, Cheng X-Y, Shao J-G, et al. Maternal hepatitis B virus carrier status and pregnancy outcomes: a prospective cohort study. BMC Pregnancy Childbirth 2016:16:1-8.

54 Ding X-X, Xu S-J, Hao J-H, et al. Maternal pre-pregnancy BMI and adverse pregnancy outcomes among Chinese women: results from the C-ABCS. J Obstet Gynaecol 2016;36:328-32.

55 Wang H, Liu L, Hu Y-F, et al. Association of maternal serum cadmium level during pregnancy with risk of preterm birth in a Chinese population. Environmental Pollution 2016;216:851-7.

56 Xue Q, Shen F, Gao Y, et al. An analysis of the medical indications for preterm birth in an obstetrics and gynaecology teaching hospital in Shanghai, China. Midwifery 2016;35:17-21.

57 Zhou SS, Ge X, Xu YQ, et al. [Previous medical or surgical abortions and subsequent risk of preterm birth: a birth cohort study]. Zhonghua Liu Xing Bing Xue Za Zhi 2016;37:1536-40.

58 Liu A, Qian N, Yu H, et al. Estimation of disease burdens on preterm births and low birth weights attributable to maternal fine particulate matter exposure in Shanghai, China. Sci Total Environ 2017;609:815-21. 
59 Reyihanguli M, Liu HY, Han WH, et al. [Influence of intrahepatic cholestasis during pregnancy on the incidence of preterm birth] Zhonghua Liu Xing Bing Xue Za Zhi 2017;38:1415-8.

60 Wang JX, Sun HQ, Huang K, et al. [Trend of caesarean section rate and puerpera characteristics: based on Robson classification]. Zhonghua Liu Xing Bing Xue Za Zhi 2017;38:963-7.

61 Wang S, Wang T, Zhang W, et al. Cohort study on maternal cytomegalovirus seroprevalence and prevalence and clinical manifestations of congenital infection in China. Medicine 2017;96:e6007.

62 Zhang Y, Gu N, Wang Z, et al. Use of the 10-Group classification system to analyze how the population control policy change in China has affected cesarean delivery. Int $J$ Gynecol Obstet 2017;138:158-63.

63 Han Y, Mao L-J, Ge X, et al. Impact of maternal thyroid autoantibodies positivity on the risk of early term birth: Ma'anshan Birth Cohort Study. Endocrine 2018;60:329-38.

64 Han Y, Jiang P, Dong T, et al. Maternal air pollution exposure and preterm birth in Wuxi, China: effect modification by maternal age. Ecotoxicol Environ Saf 2018;157:457-62.

65 Hu C-Y, Li F-L, Jiang W, et al. Pre-Pregnancy health status and risk of preterm birth: a large, Chinese, rural, population-based study. Med Sci Monit 2018;24:4718-27.

66 Lin X-H, Wu D-D, Li C, et al. Maternal high triglyceride levels during early pregnancy and risk of preterm delivery: a retrospective cohort study. $J$ Clin Endocrinol Metab 2019;104:1249-58.

67 Liu W-Y, Yu Z-B, Qiu H-Y, et al. Association between ambient air pollutants and preterm birth in Ningbo, China: a time-series study. BMC Pediatr 2018;18:305.

68 Shi WP, Qin JY, Ding Y, et al. The predictive role of transperineal ultrasound measuring anterior uterocervical angle and cervical length on preterm birth. Int J Clin Exp Med 2018;11.

69 Wang $\mathrm{H}$, Yue $\mathrm{H}$, Sun B, et al. Birth population survey in Huai'an in 2015: perinatal-neonatal mortality and preterm birth rate in emerging regions in China. J Matern Fetal Neonatal Med 2020;33:1-9.

70 Wang Y, He Y, Zhuang L, et al. Effect of maternal and neonatal factors on neonatal thyroid screening results. Clin $\mathrm{Lab}$ 2018;64:1445-50

71 Xiao Q, Chen H, Strickland MJ, et al. Associations between birth outcomes and maternal PM2.5 exposure in Shanghai: a comparison of three exposure assessment approaches. Environ Int 2018;117:226-36

72 Yang J, Chen MJ, Wang XX, et al. [Association between maternal tea consumption in pregnancy and birth outcomes]. Zhonghua $Y_{u}$ Fang Yi Xue Za Zhi 2018;52:1013-7.

73 Ye L, Ji Y, Lv W, et al. Associations between maternal exposure to air pollution and birth outcomes: a retrospective cohort study in Taizhou, China. Environ Sci Pollut Res 2018;25:21927-36.

74 Li Z-J, Liang C-M, Xia X, et al. Association between maternal and umbilical cord serum cobalt concentration during pregnancy and the risk of preterm birth: the Ma'anshan birth cohort (MABC) study. Chemosphere 2019;218:487-92.

75 Chen TJ, Lin CH, Wang CJ, et al. Vital statistics of premature and low birthweight infants in Tainan area. Zhonghua Min Guo Xiao Er Ke Yi Xue Hui Za Zhi 1996;37:439-43.

76 Lao TT, Ho LF. The obstetric implications of teenage pregnancy. Hum Reprod 1997;12:2303-5.

77 Chen Y-H, Lin H-C, Chen S-F, et al. Increased risk of preterm births among women with uterine leiomyoma: a nationwide populationbased study. Hum Reprod 2009;24:3049-56.

78 Hsieh W-S, Hsieh C-J, Jeng S-F, et al. Favorable neonatal outcomes among immigrants in Taiwan: evidence of healthy immigrant mother effect. J Womens Health 2011;20:1083-90.

79 Leung TY, Leung TN, Sahota DS, et al. Trends in maternal obesity and associated risks of adverse pregnancy outcomes in a population of Chinese women. Bjog 2008;115:1529-37.

80 Shiao LW-S, Chiang T-L. Adverse birth outcomes among nativeborn and foreign-born mothers in Taiwan: a population-based birth cohort study. BMC Pregnancy Childbirth 2012;12:110.

81 Liu C-Y, Chang N-T, Chou P. Testing the "Epidemiologic Paradox" of Birth Outcomes Among Asian Immigrant Women in Hsin-Chu County, Taiwan. J Formos Med Assoc 2008;107:782-90.

82 Xirasagar S, Fu J-C, Liu J, et al. Neonatal outcomes for immigrant vs. native-born mothers in Taiwan: an epidemiological paradox. Matern Child Health J 2011;15:269-79.

83 Lao TT, Sahota DS, Suen SSH, et al. The impact of fetal gender on preterm birth in a southern Chinese population. J Matern Fetal Neonatal Med 2011;24:1440-3.
84 Lau Y. The effect of maternal stress and health-related quality of life on birth outcomes among Macao Chinese pregnant women. $J$ Perinat Neonatal Nurs 2013;27:14-24.

85 Chung WH, Kong CW, To WW. Secular trends in caesarean section rates over 20 years in a regional obstetric unit in Hong Kong. Hong Kong Med J 2017;23:340-8.

86 Lai Y-J, Hsu T-Y, Lan K-C, et al. Asymptomatic pyuria in pregnant women during the first trimester is associated with an increased risk of adverse obstetrical outcomes. Taiwan J Obstet Gynecol 2017;56:192-5

87 Ho Y-R, Wang P, Lu M-C, et al. Associations of mid-pregnancy $\mathrm{HbA} 1 \mathrm{c}$ with gestational diabetes and risk of adverse pregnancy outcomes in high-risk Taiwanese women. PLoS One 2017;12:e0177563.

88 Chaemsaithong P, Leung TY, Sahota D, et al. Body mass index at 11-13 weeks' gestation and pregnancy complications in a southern Chinese population: a retrospective cohort study. J Matern Fetal Neonatal Med 2019;32:2056-68.

89 Zhou L-M, Yang W-W, Hua J-Z, et al. Relation of hemoglobin measured at different times in pregnancy to preterm birth and low birth weight in Shanghai, China. Am J Epidemiol 1998;148:998-1006.

90 Lin L, Liu Y, Zhang X, et al. Sampling survey on low-birth weight in China in 1998. Zhonghua Yu Fang Yi Xue Za Zhi 2002;36:149-53.

91 Liu Y, Zhang J, Li Z. Perinatal outcomes in native Chinese and Chinese-American women. Paediatr Perinat Epidemiol 2011;25:202-9.

92 Liu L, Liu J-meng, Liu Y-hui, et al. [Prevalence of preterm birth among singletons in 10 counties (cities) of China, 1993-2005]. Zhonghua Liu Xing Bing Xue Za Zhi 2007;28:1051-4.

93 Sun J, Qu S, Zhang C, et al. Neonatal mortality rate and risk factors in northeast China: analysis of 5,277 neonates in 2005. Clin Exp Obstet Gynecol 2014;41:512-6.

94 Wang T, Zhang J, Lu X, et al. Maternal early pregnancy body mass index and risk of preterm birth. Arch Gynecol Obstet 2011;284:813-9.

95 Zhang J, Liu Y, Meikle S, et al. Cesarean delivery on maternal Request in Southeast China. Obstet Gynecol 2008;111:1077-82.

96 Souza JP, Gülmezoglu A, Lumbiganon P, et al. Caesarean section without medical indications is associated with an increased risk of adverse short-term maternal outcomes: the 2004-2008 who global survey on maternal and perinatal health. BMC Med 2010;8:71.

97 Chen Y, GH L, Zou LY. [Influencing factors of low birth weight infants in China]. Chin J Perinat Med2015;18:755-60.

98 Chen Y, Wu L, Zhang W, et al. Delivery modes and pregnancy outcomes of low birth weight infants in China. $J$ Perinatol 2016;36:41-6.

99 Hou L, Wang X, Li G, et al. Cross sectional study in China: fetal gender has adverse perinatal outcomes in mainland China. BMC Pregnancy Childbirth 2014;14:372.

100 Luo X-L, Zhang W-Y. Obstetrical disease spectrum in China: an epidemiological study of 111,767 cases in 2011. Chin Med $J$ 2015;128:1137-46.

101 Ye C, Ruan Y, Zou L, et al. The 2011 survey on hypertensive disorders of pregnancy (HDP) in China: prevalence, risk factors, complications, pregnancy and perinatal outcomes. PLoS One 2014;9:e100180.

102 Souza JP, Gülmezoglu AM, Vogel J, et al. Moving beyond essential interventions for reduction of maternal mortality (the who multicountry survey on maternal and newborn health): a crosssectional study. Lancet 2013;381:1747-55.

103 Yang Y, He Y, Li Q, et al. Preconception blood pressure and risk of preterm birth: a large historical cohort study in a Chinese rural population. Fertil Steril 2015;104:124-30.

104 Huang A, Wu K, Zhao W, et al. Attendance at prenatal care and adverse birth outcomes in China: A follow-up study based on Maternal and Newborn's Health Monitoring System. Midwifery 2018;57:26-31

105 Kong X, Xu F, Wu R, et al. Neonatal mortality and morbidity among infants between 24 to 31 complete weeks: a multicenter survey in China from 2013 to 2014. BMC Pediatr 2016;16:174.

106 Li N, Li Z, Ye R, et al. Preconception blood pressure and risk of preterm birth: a large cohort study in China. $J$ Hypertens 2016:34:2243-7.

107 Tang W, Mu Y, Li X, et al. Low birthweight in China: evidence from 441 health facilities between 2012 and 2014. J Matern Fetal Neonatal Med 2017;30:1997-2002.

108 Zhang XS, Zhao GL, Yang HX. [Analysis of incidence and risk factors of preterm birth in 15 urban hospitals in China]. Chin $J$ Perinat Med 2016;19:456-61. 
109 Chen S, Zhou X, Zhu H, et al. Preconception TSH and pregnancy outcomes: a population-based cohort study in 184611 women. Clin Endocrinol 2017;86:816-24.

110 Liu J, Zhang S, Liu M, et al. Maternal pre-pregnancy infection with hepatitis $B$ virus and the risk of preterm birth: a population-based cohort study. Lancet Glob Health 2017;5:e624-32.

$111 \mathrm{Li} \mathrm{Q}$, Wang Y-Y, Guo Y, et al. Effect of airborne particulate matter of $2.5 \mu \mathrm{m}$ or less on preterm birth: A national birth cohort study in China. Environ Int 2018;121:1128-36.

$112 \mathrm{Li}$ Y, Ruan X, Wang H, et al. Comparing the risk of adverse pregnancy outcomes of Chinese patients with polycystic ovary syndrome with and without antiandrogenic pretreatment. Fertil Steril 2018;109:720-7.

113 Lin L, Wei Y, Zhu W, et al. Prevalence, risk factors and associated adverse pregnancy outcomes of anaemia in Chinese pregnant women: a multicentre retrospective study. BMC Pregnancy Childbirth 2018;18:111.

114 Wang C, Lin L, Su R, et al. Hemoglobin levels during the first trimester of pregnancy are associated with the risk of gestational diabetes mellitus, pre-eclampsia and preterm birth in Chinese women: a retrospective study. BMC Pregnancy Childbirth 2018;18:263.

115 Wang Y-yuan, Li Q, Guo Y, et al. Association of long-term exposure to airborne particulate matter of $1 \mu \mathrm{m}$ or less with preterm birth in China. JAMA Pediatr 2018:172:e174872.

116 Zhang X, Xu Q, Yang Y, et al. Preconception $\mathrm{Hb}$ concentration and risk of preterm birth in over 2.7 million Chinese women aged 20-49 years: a population-based cohort study. Br J Nutr 2018;120:508-16.

117 Zhang JH, Yuan L, Yang YH. [Perinatal colonization of group B streptococcus: a study in 600 cases in Beijing Tiantan Hospital]. Zhonghua Liu Xing Bing Xue Za Zhi 1995;16:36-9.

118 Ye R, Zhang L, Yang Z. [Obstetrical outcome of pregnancy on in vitro fertilization and embryo transfer 128 cases analysis]. Zhonghua Fu Chan Ke Za Zhi 2000;35:157-9.

119 Gao X, Liu Y, SJCJoPM Z. The clinical analysis of 433 cases of preterm birth, 2000.

120 Qi L, Wang S, Liang J, et al. Influence of abnormal cervical Pap smear undertaken during pregnancy to the outcome of the pregnancy. Zhonghua Fu Chan Ke Za Zhi 2002;37:388-90.

121 Zhang XF, Liu XM, Liu XL, et al. Retrospective analysis of 545 cases of neonatal asphyxia. Chinese Journal Of Perinatal Medicine 2007:10:240-3.

122 Guo Z-kun, Ma J-mei, Fan L, et al. [Preterm birth and preterm infants in Beijing regional district]. Zhonghua Fu Chan Ke Za Zhi 2010:45:99-103.

123 Sun $\mathrm{Y}$, Chen $\mathrm{Q}$, Bian XM, et al. [Intrauterine infection and the perinatal outcomes in seven tertiary hospitals in Beijing]. Chinese Journal Of Perinatal Medicine 2009;5.

124 Qin B-L, Zhang W-Y, Dang Y-L, et al. [Analysis of related factors of premature delivery for the migrant population in local suburban Beijing areas]. Zhonghua Yi Xue Za Zhi 2011;91:2340-2.

125 Ma L, Liu C-ging, Zheng X-ling, et al. A 12-month prospective survey of perinatal outcome of liveborn neonates in Julu County, China. Chin Med J 2010;123:2781-5.

126 Qu S-hui, Shi C-yan, Chen Q, et al. [Predictive value of cervical length by transvaginal sonography for preterm pregnancy during mid- and late-trimester of pregnancy]. Zhonghua Fu Chan Ke Za Zhi 2011;46:748-52.

127 Wei Y-mei, Yang H-xia. [Comparison of the diagnostic criteria for gestational diabetes mellitus in China]. Zhonghua Fu Chan Ke Za Zhi 2011:46:578-81.

128 Zhao DQ, Yang HX, Wei YM, et al. [Association between fasting plasma glucose in early pregnancy and diagnosis of gestational diabetes mellitus]. Chin J Perinat Med 2011:14:210-4.

129 Liu J-meng, Mei Z, Ye R, et al. Micronutrient supplementation and pregnancy outcomes: double-blind randomized controlled trial in China. JAMA Intern Med 2013;173:276-82.

130 Shan X, Chen F, Wang W, et al. Secular trends of low birthweight and macrosomia and related maternal factors in Beijing, China: a longitudinal trend analysis. BMC Pregnancy Childbirth 2014;14:105.

131 Hu X-yu, Bian X-ming, Jiang Y-lin, et al. [Relationship of adverse pregnancy outcomes and a high risk serum screen for Down syndrome in the second trimester]. Zhonghua Fu Chan Ke Za Zhi 2012:47:427-30.

132 Zhou Q, XY H, Jiang YL, et al. [Maternal serum markers for Down syndrome screening in second-trimester and its relations with adverse pregnant outcomes]. Chin J Perinat Med 2013;16:555-60.

133 Wang SY, Zhu WW, Yang HX. [Relationship between fasting plasma glucose in early pregnancy and diagnosis of gestational diabetes mellitus]. Chin J Perinat Med 2013;16:45-50.
134 Liu XH, Gao SH, Wang JM, et al. [The influence of subclinical hypothyroidism on pregrency outcomes]. Chin J Perinat Med 2012;15:696-700.

135 Wang C-shu, Wei Y-mei, Yang $\mathrm{H}$-xia. [Analysis of the effects of gestational diabetes mellitus based on abnormal blood glucose on pregnancy outcomes]. Zhonghua Fu Chan Ke Za Zhi 2013;48:899-902.

136 Zhang $\mathrm{CH}$, Liu XY, Zhan YW, et al. Effects of prepregnancy body mass index and gestational weight gain on pregnancy outcomes. Asia Pac J Public Health 2015;27:620-30.

137 Shang M, Lin L. IADPSG criteria for diagnosing gestational diabetes mellitus and predicting adverse pregnancy outcomes. $J$ Perinatol 2014;34:100-4.

138 Wen T, Lv Y. Inadequate gestational weight gain and adverse pregnancy outcomes among normal weight women in China. Int $J$ Clin Exp Med 2015;8:2881-6.

139 Barros FC, Papageorghiou AT, Victora CG, et al. The distribution of clinical phenotypes of preterm birth syndrome: implications for prevention. JAMA Pediatr 2015;169:220-9.

140 Han S, Yang X, Zhou Y, et al. Deafness gene mutations in newborns in Beijing. Acta Otolaryngol 2016;136:475-9.

141 Maerdan M, Shi C, Zhang X, et al. The prevalence of short cervix between 20 and 24 weeks of gestation and vaginal progesterone for prolonging of gestation. J Matern Fetal Neonatal Med 2017;30:1646-9.

142 Wei Y-M, Yang H-X, Zhu W-W, et al. Risk of adverse pregnancy outcomes stratified for pre-pregnancy body mass index. J Matern Fetal Neonatal Med 2016;29:2205-9.

143 Cheng Y, Feng Y, Duan X, et al. [Ambient PM2.5 during pregnancy and risk on preterm birth]. Zhonghua Liu Xing Bing Xue Za Zhi 2016;37:572-7.

144 Jiang F, Gao J-S, Zhong Y-F, et al. Preterm births in Peking Union medical college hospital in the past 25 years. Zhongguo Yi Xue Ke Xue Yuan Xue Bao 2016;38:528-33.

145 Yang W, Han F, Gao X, et al. Relationship between gestational weight gain and pregnancy complications or delivery outcome. Sci Rep 2017;7:12531.

146 Wang C, Wang XY, Yang HX. [Effect of maternal age on pregnancy outcomes in Beijing]. Zhonghua Fu Chan Ke Za Zhi 2017:52:514-20.

147 Zheng W, Huang W, Zhang L, et al. Changes in serum lipid levels during pregnancy and association with neonatal outcomes: a large cohort study. Reprod Sci 2018;25:1406-12.

148 Zhang X, Liu KB, Liu FJ, et al. [Clinical characteristics and pregnancy outcomes of pregnant women in different age groups in Beijing]. Zhonghua Fu Chan Ke Za Zhi 2018;53:452-8.

149 Wang S, Teng WP, Li JX, et al. Effects of maternal subclinical hypothyroidism on obstetrical outcomes during early pregnancy. $J$ Endocrinol Invest 2012;35:322-5.

$150 \mathrm{XY} X$, Zhou M, XC H, et al. Influence factors of body mass index before pregnancy and the relationship with gestational weight gain,maternal and infants complications. Chin J Perinat Med 2015;18:352-8.

151 Jiang M, Qiu J, Zhou M, et al. Exposure to cooking fuels and birth weight in Lanzhou, China: a birth cohort study. BMC Public Health 2015; $15: 712$.

152 Zhao N, Qiu J, Zhang Y, et al. Ambient air pollutant PM10 and risk of preterm birth in Lanzhou, China. Environ Int 2015;76:71-7.

153 Huang L, Lerro C, Yang T, et al. Maternal tea consumption and the risk of preterm delivery in urban China: a birth cohort study. BMC Public Health 2016;16:456.

154 Wang LL, Bai RH, Liu Q, et al. [Epidemiological study on adverse pregnancy outcomes in Shaanxi province]. Zhonghua Liu Xing Bing Xue Za Zhi 2016;37:1379-82.

155 Yang J, Cheng Y, Pei L, et al. Maternal iron intake during pregnancy and birth outcomes: a cross-sectional study in northwest China. $\mathrm{Br}$ J Nutr 2017;117:862-71.

156 Zhu XY, Wang CH, JQ S, et al. Retrospective analysis on implementing new guidelines of neonatal resuscitation program in 6885 newborns]. Chinese Journal Of Perinatal Medicine 2007;10:230-3

157 Fu J, Yu M. A hospital-based birth weight analysis using computerized perinatal data base for a Chinese population. $J$ Matern Fetal Neonatal Med 2011;24:614-8.

158 Zhou J, Su L, Liu M, et al. Associations between 25-hydroxyvitamin D levels and pregnancy outcomes: a prospective observational study in southern China. Eur $\mathrm{J}$ Clin Nutr 2014:68:925-30.

159 Lei Q, Niu JM, Duan DM, et al. Relationship between abnormality of lipid metabolism druing midterm pregnancy with adverse pregnancy outcomes. Chin J Perinat Med 2014:17:527-30. 
160 He J-R, Liu Y, Xia X-Y, et al. Ambient temperature and the risk of preterm birth in Guangzhou, China (2001-2011). Environ Health Perspect 2016;124:1100-6.

161 Lei Q, Niu J, Lv L, et al. Clustering of metabolic risk factors and adverse pregnancy outcomes: a prospective cohort study. Diabetes Metab Res Rev 2016;32:835-42.

162 Liang Z, Lin Y, Ma Y, et al. The association between ambient temperature and preterm birth in Shenzhen, China: a distributed lag non-linear time series analysis. Environ Health 2016;15:84.

163 Shen S, Lu J, Zhang L, et al. Single fasting plasma glucose versus $75-g$ oral glucose-tolerance test in prediction of adverse perinatal outcomes: a cohort study. EBioMedicine 2017;16:284-91.

$164 \mathrm{Ke} \mathrm{L}$, Lin W, Liu Y, et al. Association of induced abortion with preterm birth risk in first-time mothers. Sci Rep 2018;8:5353.

165 Li C, Liang Z, Bloom MS, et al. Temporal trends of preterm birth in Shenzhen, China: a retrospective study. Reprod Health 2018;15:47.

166 Liang Z, Wang P, Zhao Q, et al. Effect of the 2008 cold spell on preterm births in two subtropical cities of Guangdong Province, southern China. Sci Total Environ 2018;642:307-13.

167 Wang $Q$, Benmarhnia $T$, Zhang $H$, et al. Identifying windows of susceptibility for maternal exposure to ambient air pollution and preterm birth. Environ Int 2018;121:317-24.

168 Yangzom Y, Qian L, Shan M, et al. Outcome of hospital deliveries of women living at high altitude: a study from Lhasa in Tibet. Acta Paediatr 2008;97:317-21.

169 Yang X, Zeng W. Clinical analysis of 828 cases of iatrogenic preterm births. J Obstet Gynaecol Res 2011;37:1048-53.

170 Duan L, Yan D, Zeng W, et al. Effect of progesterone treatment due to threatened abortion in early pregnancy for obstetric and perinatal outcomes. Early Hum Dev 2010;86:41-3.

171 Tan CE, Li HJ, Zhang XG, et al. The impact of the Wenchuan earthquake on birth outcomes. PLoS One 2009;4:e8200.

172 Liao H, Wei Q, Duan L, et al. Repeated medical abortions and the risk of preterm birth in the subsequent pregnancy. Arch Gynecol Obstet 2011;284:579-86.
173 Liao S, Mei J, Song W, et al. The impact of the International association of diabetes and pregnancy study groups (IADPSG) fasting glucose diagnostic criterion on the prevalence and outcomes of gestational diabetes mellitus in Han Chinese women. Diabet Med 2014;31:341-51.

174 Fan X-J, Gao J-M, Kang Y-J, et al. Socioeconomic and environmental determinants to preterm birth in Tibetan women: an analysis based on the hierarchically conceptual frame. Chin Med J 2017;130:2307-15.

175 Li R, Zhang J, Zhou R, et al. Sleep disturbances during pregnancy are associated with cesarean delivery and preterm birth. J Matern Fetal Neonatal Med 2017;30:733-8.

176 The subspecialty group of Obstetrics OaGS, Chinese Medical Association. Guidelines for clinical diagnosis and treatment of premature delivery. Chinese Journal of Obstetrics and Gynecology 2014;49:481-5.

177 Morisaki N, Ganchimeg T, Vogel JP, et al. Impact of stillbirths on international comparisons of preterm birth rates: a secondary analysis of the who multi-country survey of maternal and newborn health. BJOG: Int J Obstet Gy 2017;124:1346-54.

178 Qiao J, Feng HL. Assisted reproductive technology in China: compliance and non-compliance. Trans/ Pediatr 2014;3:91-7.

179 Jančar N, Mihevc Ponikvar B, Tomšič S, et al. Is IVF/ICSI an independent risk factor for spontaneous preterm birth in singletons? a population-based cohort study. Biomed Res Int 2018;2018:1-8.

180 Martin J, Hamilton B, Osterman M, et al. National vital statistics reports. births: final data for 2013, 2015

181 Blumenshine P, Egerter S, Barclay CJ, et al. Socioeconomic disparities in adverse birth outcomes: a systematic review. Am J Prev Med 2010;39:263-72.

182 Morisaki N, Ogawa K, Urayama KY, et al. Preeclampsia mediates the association between shorter height and increased risk of preterm delivery. Int J Epidemiol 2017;46:1690-8.

183 Liu L, YL L. [Correlation of geographical latitude with stature and body weight of urban Han people in China]. Chinese Journal of Anatomy 2017;40:307-10 